\title{
Green synthesis of multifunctional silver and gold nanoparticles from the oriental herbal adaptogen: Siberian ginseng
}

This article was published in the following Dove Press journal:

International Journal of Nanomedicine

II July 2016

Number of times this article has been viewed

\author{
Ragavendran Abbai ${ }^{1, *}$ \\ Ramya Mathiyalagan ${ }^{1, *}$ \\ Josua Markus' \\ Yeon-Ju Kim² \\ Chao Wang ${ }^{2}$ \\ Priyanka Singh ${ }^{2}$ \\ Sungeun $\mathrm{Ahn}^{2}$ \\ Mohamed El-Agamy Farh² \\ Deok Chun Yang ${ }^{1,2}$ \\ 'Ginseng Bank, Graduate School \\ of Biotechnology, ${ }^{2}$ Department of \\ Oriental Medicinal Biotechnology, \\ College of Life Sciences, Kyung Hee \\ University, Yongin, Republic of Korea \\ *These authors contributed equally \\ to this work
}

\begin{abstract}
Pharmacologically active stem of the oriental herbal adaptogen, Siberian ginseng, was employed for the ecofriendly synthesis of Siberian ginseng silver nanoparticles (Sg-AgNPs) and Siberian ginseng gold nanoparticles (Sg-AuNPs). First, for metabolic characterization of the sample, liquid chromatography-tandem mass spectrometry analysis (indicated the presence of eleutherosides A and E), total phenol content, and total reducing sugar were analyzed. Second, the water extract of the sample mediated the biological synthesis of both Sg-AgNPs and Sg-AuNPs that were crystalline face-centered cubical structures with a Z-average hydrodynamic diameter of 126 and $189 \mathrm{~nm}$, respectively. Moreover, Fourier transform infrared analysis indicated that proteins and aromatic hydrocarbons play a key role in the formation and stabilization of $\mathrm{Sg}$ AgNPs, whereas phenolic compounds accounted for the synthesis and stability of Sg-AuNPs. 3-(4,5-Dimethyl-2-thiazolyl)-2,5-diphenyl-2H tetrazolium bromide (MTT) assay determined that $\mathrm{Sg}$-AgNPs conferred strong cytotoxicity against MCF7 (human breast cancer cell line) and was only slightly toxic to $\mathrm{HaCaT}$ (human keratinocyte cell line) at $10 \mu \mathrm{g} \cdot \mathrm{mL}^{-1}$. However, Sg-AuNPs did not display cytotoxic effects against both of the cell lines. The disc diffusion assay indicated a dose-dependent increase in the zone of inhibition of Staphylococcus aureus (ATCC 6538), Bacillus anthracis (NCTC 10340), Vibrio parahaemolyticus (ATCC 33844), and Escherichia coli (BL21) treated with Sg-AgNPs, whereas Sg-AuNPs did not show inhibitory activity. In addition, the 2,2-diphenyl-1-picrylhydrazyl assay demonstrated that both Sg-AgNPs and Sg-AuNPs possess strong antioxidant activity. To the best of our knowledge, this is the first report unraveling the potential of Eleutherococcus senticosus for silver and gold nanoparticle synthesis along with its biological applications, which in turn would promote widespread usage of the endemic Siberian ginseng.
\end{abstract}

Keywords: Siberian ginseng, eleutheroside E, eleutheroside A, green synthesis, cytotoxicity, antibacterial activity, antioxidant efficacy

\section{Introduction}

Nanobiotechnology is a blend of nanotechnology and biotechnology that chiefly involves the application of nanoparticles to shed light on the development of novel strategies used to address biological issues. Nanoparticles play a pivotal role in cancer therapy, drug delivery, and also in other biomedical applications. ${ }^{1}$ Among them, metal and polymer nanoparticles are commonly analyzed for application in the medicinal field. ${ }^{2-4}$ In addition, metal nanoparticles have inherent biological activities and are compatible for therapeutic applications. ${ }^{5,6}$ Therefore, there is an imperative need to establish a methodology for their large-scale synthesis. Usually, their mass production is performed through various physical and chemical methods, which 
often results in the accumulation of toxic chemicals in the environment, thereby posing a threat to human, animal, and plant health. ${ }^{7}$ Green synthesis is one of the best alternatives owing to its ecofriendly nature. In this regard, plant and microbe-mediated synthesis has been attempted in the past, and the plant system was found to be much faster than using a microbial system. Moreover, the green synthesized nanoparticles also exhibit strong cytotoxic, antimicrobial, and antioxidant activities..$^{2,8,9}$

Among medicinal plant sources, Siberian ginseng (Eleutherococcus senticosus) is widely used in oriental medicine. It belongs to the Araliaceae family and is predominantly found in Russia, People's Republic of China, Korea, and Japan. It is considered to be an adaptogen and is chiefly exploited for strengthening the spleen and kidney. ${ }^{10,11}$ Eleutherosides, the major bioactive compounds found in E. senticosus, are phenylpropanoids, lignin glycosides that occur abundantly in the roots and stems. ${ }^{12}$ E. senticosus has been proven to possess anticancer, ${ }^{13}$ antioxidant, and antimicrobial activities. ${ }^{13-15}$

We hypothesize that silver and gold nanoparticles from E. senticosus would exhibit strong biological activities, similar to that of the precursors. In addition, E. senticosus is a perennial plant and is endemic to certain geographical locations. Therefore, the option of utilizing the nanoparticles synthesized from Siberian ginseng would enable its widespread usage in the medicinal field. Initially, liquid chromatography-tandem mass spectrometry (LC-MS/MS) analysis of the ethanolic extract indicated the presence of eleutherosides A and E. Folin-Ciocalteu (F-C) analysis and a 3,5-dinitrosalicylic acid (DNS) assay were performed to determine the quantity of total phenolics and the total reducing sugars. Following that, the water extract of the sample was used for the synthesis of Siberian ginseng silver nanoparticles (Sg-AgNPs) and Siberian ginseng gold nanoparticles (Sg-AuNPs). Physicochemical techniques, namely ultraviolet-visible (UV-Vis) spectrophotometry, field emission transmission electron microscopy (FE-TEM), energy dispersive X-ray spectroscopy (EDX), selected area electron diffraction pattern, dynamic light scattering particle size analysis, X-ray diffraction analysis, and Fourier transform infrared analysis (FTIR), aided in the elucidation of their morphological and chemical nature. Finally, the synthesized nanoparticles were investigated for their cytotoxic potential (against MCF7, a breast cancer cell line, and $\mathrm{HaCaT}$, a human keratinocyte cell line), antibacterial (against Staphylococcus aureus, Bacillus anthracis, Vibrio parahaemolyticus, and Escherichia coli), and antioxidant potentials (2,2-diphenyl-1-picrylhydrazyl [DPPH] analysis).

\section{Materials and methods Materials}

The dried stem portion of $E$. senticosus (after removing thorns) was obtained from the Ginseng bank, Kyung Hee University, South Korea. Silver nitrate $\left(\mathrm{AgNO}_{3}\right)$ and Gold (III) chloride trihydrate $\left(\mathrm{HAuCl}_{4} \cdot 3 \mathrm{H}_{2} \mathrm{O}\right)$ were purchased from Sigma-Aldrich Co. (St Louis, MO, USA). The rest of the chemicals used in this study were of analytical grade and used as received.

\section{Metabolic analyses of E. senticosus}

\section{Sample preparation}

A $50 \%$ ethanol solution was reported to be the best solvent for eleutheroside detection. ${ }^{16}$ Hence, $3 \mathrm{~g}$ of coarsely ground dried stem of E. senticosus was extracted with $30 \mathrm{~mL}$ of $50 \%$ ethanol under reflux for 1 hour. The extract was then filtered and evaporated in a rotary evaporator. After complete evaporation, $1 \mathrm{~mL}$ of high-performance liquid chromatography grade methanol was added, and the extract was used for LC-MS profiling. In a similar fashion, the extract was prepared for the total phenolic assay and total reducing sugar analysis.

\section{LC-MS/MS for the detection of eleutherosides}

LC-MS/MS analysis was performed as previously described with minor modifications. ${ }^{16}$ The experimental conditions are as follows: a negative mode of electrospray ionization (ESI) was employed with gas temperature of $350^{\circ} \mathrm{C}$, nebulizer gas flow rate of $5 \mathrm{~L} \mathrm{~min}^{-1}$, at $60 \mathrm{psi}$, with capillary voltage of $2,500 \mathrm{~V}$. Approximately $0.1 \%$ ammonium hydroxide was used as the solvent.

\section{Total phenolic assay}

The total phenolic content in the $50 \%$ ethanolic extract of E. senticosus was determined by the F-C method with minor modifications. ${ }^{17}$ Approximately $1 \mathrm{~mL}$ of the methanol extract was added to $1 \mathrm{~mL}$ of $10 \%$ sodium bicarbonate and incubated at room temperature for 5 minutes after vortexing. Following this, $1 \mathrm{~mL}$ of $2 \mathrm{~N} \mathrm{F-C}$ reagent was added to the mixture, it was then vortexed, and incubated in the dark for 30 minutes. The absorbance was then recorded at $765 \mathrm{~nm}$. The total phenolic content was calculated by using gallic acid as the standard. The analysis was performed in triplicate to ensure accuracy of the results.

\section{Estimation of total reducing sugars}

The DNS method was employed to determine the content of total reducing sugars in the E. senticosus extract. DNS reagent was prepared in line with the previously established 
method. ${ }^{18}$ For the analysis, $1 \mathrm{~mL}$ of the DNS reagent was added to $1 \mathrm{~mL}$ of extract, which was then boiled at $90^{\circ} \mathrm{C}$ for 10 minutes. The absorbance was then measured at $540 \mathrm{~nm}$ after the reaction mixture was cooled to room temperature. The total reducing sugar content was estimated using glucose as the standard. Three replicates were carried out to prove the reproducibility of the experiment.

\section{Preparation of crude extract for nanoparticle synthesis}

The dried stem portion of E. senticosus was powdered using a commercial blender. Approximately $10 \mathrm{~g}$ of the coarse powder was boiled $\left(100^{\circ} \mathrm{C}\right)$ in $150 \mathrm{~mL}$ of sterile water for 30 minutes. The collected extract was filtered and then centrifuged at $10,000 \mathrm{rpm}$ for 10 minutes to remove the suspended materials. The collected supernatant was stored at $-20^{\circ} \mathrm{C}$ and was used as a stock solution for the synthesis of silver and gold nanoparticles.

\section{Synthesis of silver and gold nanoparticles} Approximately $1 \mathrm{mM}$ silver nitrate $\left(\mathrm{AgNO}_{3}\right)$ and gold (III) chloride trihydrate $\left(\mathrm{HAuCl}_{4} \cdot 3 \mathrm{H}_{2} \mathrm{O}\right)$ were used for E. senticosus-mediated nanoparticle synthesis. The syntheses of silver and gold nanoparticles were carried out using various concentrations of the plant extract $(1: 1,1: 2$, and $1: 3$ dilutions of the extract). The concentration that gave the best results was further tested across different temperatures $\left(\sim 23^{\circ} \mathrm{C}, 40^{\circ} \mathrm{C}\right.$, and $80^{\circ} \mathrm{C}$ ) and various time intervals. The reaction mixture was centrifuged at 17,000 rpm for 20 minutes for the extraction of $\mathrm{Sg}$-AgNPs and Sg-AuNPs. The pelleted particles were further purified by recurring centrifugation and dispersion in sterile water three times to remove the water soluble biomolecules that were present. From this experiment, the best synthesis conditions were established, and these conditions were employed for the mass production of nanoparticles for further characterization and evaluation of their biological activities.

\section{Characterization of synthesized nanoparticles}

To confirm the reduction of the silver salt, the appropriate reaction mixture was scanned between 300 and $800 \mathrm{~nm}$ in a UV-Vis spectrophotometer (2100 Pro; Amersham Biosciences Corp., Piscataway, NJ, USA). The morphology and elemental distribution of the nanoparticles were evaluated using Ultrospec (FE-TEM), EDX, and elemental mapping with a JEM-2100F (JEOL, Tokyo, Japan) operated at $200 \mathrm{kV}$. The nanoparticle samples were loaded on a carbon-coated copper grid and oven dried at $60^{\circ} \mathrm{C}$ before microscopic analysis.
Dynamic light scattering analysis was carried out with a particle size analyzer (Photal; Otsuka Electronics Co., Osaka, Japan) at $25^{\circ} \mathrm{C}$ to determine the hydrophobic diameter and polydispersity index of the Sg-AgNPs and Sg-AuNPs. Pure water (refractive index of 1.3328 ; viscosity of 0.8878 ; dielectric constant of 78.3) was used as the reference dispersive medium. Nanoparticle samples that were washed with water three times and air dried were used for the X-ray diffraction and FTIR analyses. An X-ray diffractometer, D8 Advance (Bruker, Billerica, MA, USA), with a set of defined configurations $(40 \mathrm{kV} ; 40 \mathrm{~mA}$; $\mathrm{CuK} \alpha$ radiation $1.54 \AA$; a scanning rate of $6^{\circ} / \mathrm{min}$; step size 0.02 ; over the $2 \theta$ range of $20^{\circ}-80^{\circ}$ ) was used to confirm the three dimensional configuration and crystallinity of the nanoparticles. FTIR was performed using a FTIR spectrophotometer (PerkinElmer Inc., Waltham, MA, USA) in the range of $450-4,000 \mathrm{~cm}^{-1}$ at a resolution of $4 \mathrm{~cm}^{-1}$. The stability of Sg-AgNPs and Sg-AuNPs was analyzed after incubating them at room temperature for a period of 1 month. The absorbance was then measured by UV-Vis spectrophotometer to check the stability.

\section{Evaluating the biological activities of $\mathrm{Sg}-\mathrm{AgNPs}$ and Sg-AuNPs}

\section{Anticancer activity}

The cytotoxicity of Sg-AgNPs and Sg-AuNPs against the HaCaT and MCF7 cell lines was analyzed by MTT assay. ${ }^{8}$ These cells were seeded onto 96-well plates at a density of $1 \times 10^{4}$ per well (Corning Costar, Lowell, NY, USA) and were then treated with different concentrations of Sg-AgNPs and Sg-AuNPs $\left(1,10\right.$, and $\left.100 \mu \mathrm{g} \cdot \mathrm{mL}^{-1}\right)$ for 72 hours. Approximately $10 \mu \mathrm{L}$ of MTT solution $\left(5 \mu \mathrm{g} \cdot \mathrm{mL}^{-1}\right)$ was then added to each well and incubated for another 4 hours. Following this, all of the solutions were removed by aspiration, and the resulting formazan product was dissolved in $100 \mu \mathrm{L}$ of dimethyl sulfoxide (DMSO) and incubated in the dark for 30 minutes. The absorbance of each well was recorded at $570 \mathrm{~nm}$ on a microplate reader (Bio-Tek Instruments, Inc., Vinooski, VT, USA). Untreated cells were used as the control.

\section{Antibacterial activity}

The antibacterial activity of Sg-AgNPs and Sg-AuNPs were evaluated against $S$. aureus (ATCC 6538), B. anthracis (NCTC 10340), V. parahaemolyticus (ATCC 33844), and E. coli (BL21) by the disc diffusion assay. An overnight $\log$ culture $(100 \mu \mathrm{L}$ of 0.2 optical density [OD] at $600 \mathrm{~nm})$ of these microbes was evenly spread on Luria-Bertani agar plates. Following this, autoclaved paper discs were placed in the plates. Three different concentrations of Sg-AgNPs 
and Sg-AuNPs namely 10, 20, and $30 \mu \mathrm{g} \cdot \mathrm{mL}^{-1}$ were added to these paper discs. Subsequently, the plates were incubated at $37^{\circ} \mathrm{C}$, and after 24 hours they were analyzed for antimicrobial effects. This experiment was performed in triplicate to confirm the accuracy and precision.

\section{Antioxidant activity (DPPH analysis)}

The antioxidant activity of Sg-AgNPs and Sg-AuNPs was determined through DPPH analysis with minor modifications. ${ }^{19}$ Four different concentrations of nanoparticles $(50,100,250$, and $500 \mu \mathrm{g} \cdot \mathrm{mL}^{-1}$ ) were mixed with $1 \mathrm{~mL}$ of $0.1 \mathrm{mM} \mathrm{DPPH}$ and then incubated in the dark for 30 minutes. Subsequently, the absorbance was measured at $517 \mathrm{~nm}$ with ascorbic acid as the positive control. The free radical scavenging activity was determined by the formula, $\%$ inhibition $=([$ control OD - sample OD]/control OD) $\times 100$. Three replications were performed to enhance the reliability of the analysis.

\section{Results and discussion}

A schematic overview of the Siberian ginseng-mediated synthesis of silver and gold nanoparticles is depicted in Figure 1.

\section{Metabolic analyses of E. senticosus}

LC-MS profiling, total phenolic analysis, and total reducing sugar assay were performed in order to metabolically characterize the sample. In the present study, LC-MS analysis of the ethanolic extract revealed the presence of eleutheroside
A corresponding to $\mathrm{m} / \mathrm{z} 396$, which could be correlated to the loss of O-glucose, while eleutheroside $\mathrm{E}$ was observed at $\mathrm{m} / \mathrm{z} 401$, owing to the loss of O-glucose and glucose (Figure 2), as reported in an earlier study. ${ }^{16}$

The F-C method was utilized to profile the total phenolics. This method relies on the movement of electrons from phenolic compounds to the phosphomolybdic/phosphotungstic acid complexes under alkaline conditions, resulting in a color change, which is determined spectrometrically at $765 \mathrm{~nm} .{ }^{20}$ The total phenolic content was estimated to be around $241 \mu \mathrm{g} \cdot \mathrm{mL}^{-1}$ of the extract. DNS analysis was used to detect the total reducing sugars present in the sample. DNS (yellow color) is reduced to 3-amino-5-nitro salicylic acid (orange-red color) by the reducing sugars in the presence of a strong base, which can be detected by the change in absorbance. ${ }^{21,22}$ The total amount of reducing sugars was found to be $4.5 \mathrm{mg} \cdot \mathrm{mL}^{-1}$ of the extract.

\section{Optimization of conditions for synthesis of Sg-AgNPs and Sg-AuNPs}

The standardization of reaction conditions was performed to determine optimal concentration of plant extract, temperature, and time. For the synthesis of silver nanoparticles, the addition of $1 \mathrm{mM} \mathrm{AgNO}$ to $1: 1$ diluted plant extract incubated at $80^{\circ} \mathrm{C}$ for 1.5 hours showed the best results. Whereas, in the case of synthesis of gold nanoparticle, addition of $1 \mathrm{mM} \mathrm{HAuCl} \cdot 3 \mathrm{H}_{2} \mathrm{O}$ to $1: 1$ diluted plant extract incubated at

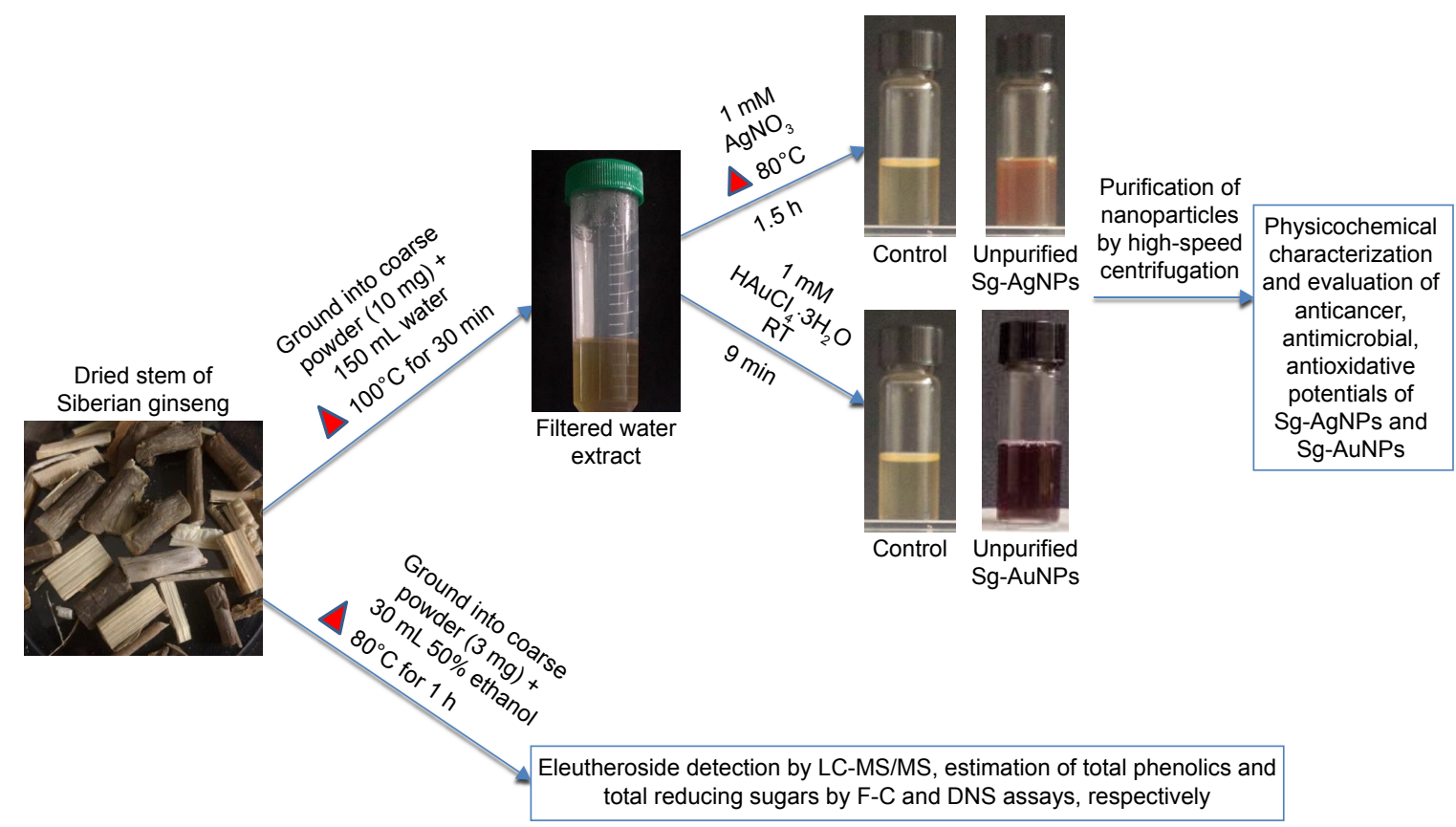

Figure I Schematic overview of the Siberian ginseng-mediated silver and gold nanoparticle synthesis and evaluation of their biological activities. Abbreviations: DNS, 3,5-dinitrosalicylic acid; F-C, Folin-Ciocalteu; LC-MS/MS, liquid chromatography-tandem mass spectrometry; RT, room temperature; Sg-AgNPs, Siberian ginseng silver nanoparticles; Sg-AuNPs, Siberian ginseng gold nanoparticles; h, hours; min, minutes. 

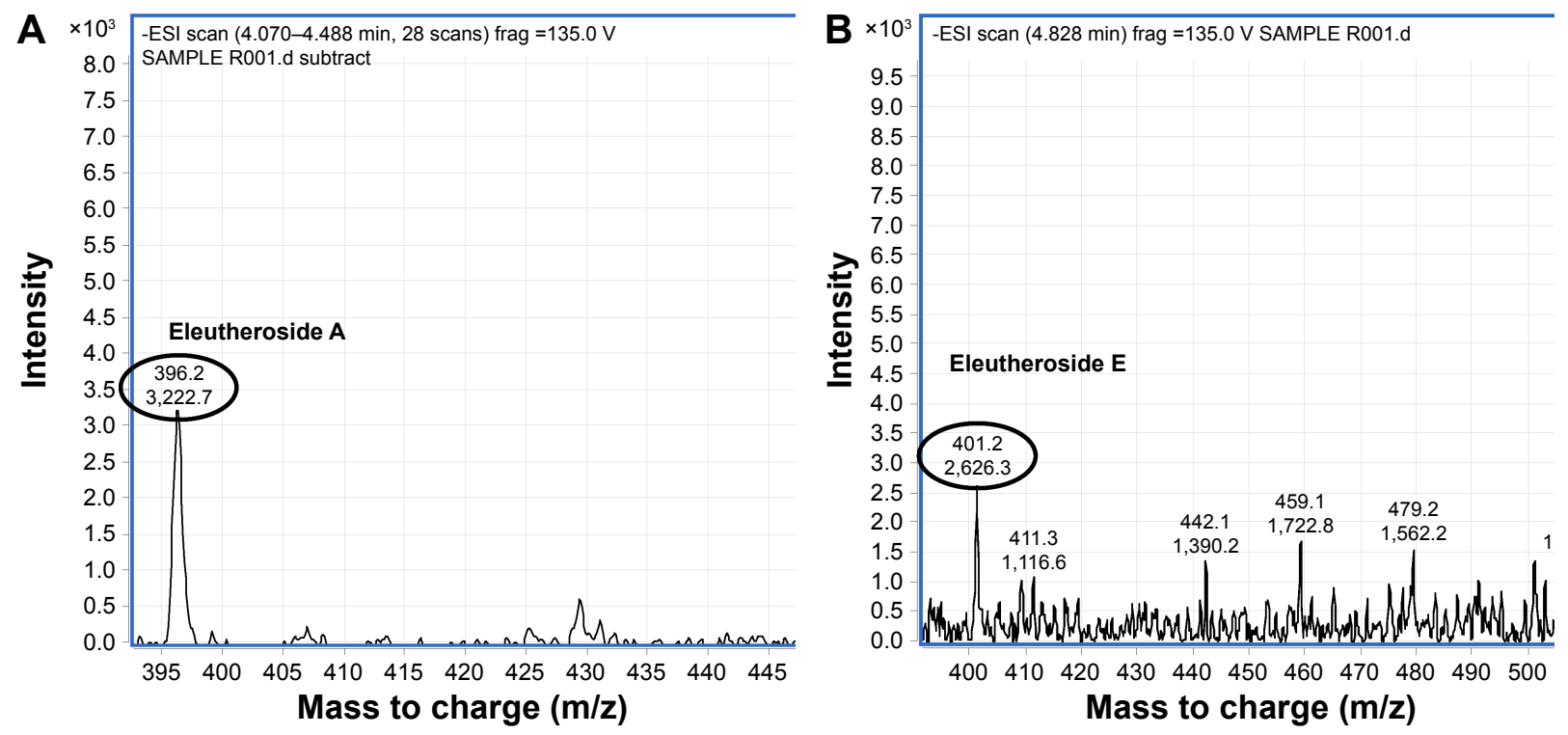

Figure 2 LC-MS/MS analyses of the ethanolic extract confirmed the presence of eleutheroside A with m/z 396 [M-(O-Glc) $]^{-}$(A) and eleutheroside E with m/z 40 I $[\mathrm{M}-(\mathrm{O}-\mathrm{Glc}-\mathrm{Glc})]^{-}(\mathbf{B})$.

Abbreviations: LC-MS/MS, liquid chromatography-tandem mass spectrometry; ESI, electrospray ionization.

room temperature for 9 minutes was preferred. Based on the UV-Vis data, it was inferred that temperature did not play a major role in the synthesis of gold nanoparticles (Figure 3). These optimized conditions were used for mass production of nanoparticles for further analyses.

\section{Synthesis and physiochemical characterization of silver and gold nanoparticles}

The crude extract of E. senticosus exhibited the capacity to reduce $\mathrm{AgNO}_{3}$ and $\mathrm{HAuCl}_{4} \cdot 3 \mathrm{H}_{2} \mathrm{O}$ to result in the formation of silver and gold nanoparticles, respectively, which was indicated by the color change in the reaction mixture. Approximately $1 \mathrm{mM}$ of $\mathrm{AgNO}_{3}$ was completely reduced to Sg-AgNPs upon incubation at $80^{\circ} \mathrm{C}$ for 1.5 hours, which was indicated by the change in color of the reaction mixture from light yellow to dark brown. In addition, time-dependent UV spectroscopy over the range of $300-800 \mathrm{~nm}$ resulted in a strong peak at approximately $440 \mathrm{~nm}$, which could be attributed to the surface plasmon resonance band of the silver nanoparticles (Figure $3 \mathrm{~A}$ ). Upon the addition of $1 \mathrm{mM} \mathrm{HAuCl}_{4} \cdot 3 \mathrm{H}_{2} \mathrm{O}$ in the reaction mixture at room temperature, its color changed from light yellow to deep purple. Time-dependent UV spectroscopy over the range of 300-800 nm revealed the peak at $575 \mathrm{~nm}$, corresponding to the surface plasmon resonance band of gold nanoparticles (Figure 3D). For the spectrometric analysis, the absorption spectrum of the extract was used as the control.

TEM analysis exhibits 1,000-fold more resolution than SEM and hence is most commonly used for analyzing the shape of the nanoparticles. ${ }^{23}$ FE-TEM analysis indicated that both the silver and gold nanoparticles were predominantly spherical (Figure 4). Their purity and elemental composition were analyzed through EDX and elemental mapping (Figure 4). In the EDX spectrum, the silver and gold nanoparticles exhibited an optical absorption band peak at $\sim 3$ and $2.3 \mathrm{keV}$, respectively. These results are in line with the previous reports. ${ }^{9,24}$ The dynamic light scattering particle size analysis revealed that the Z-average hydrodynamic diameters of Sg-AgNPs and Sg-AuNPs were approximately 126 and $189 \mathrm{~nm}$, respectively (Figure 5). The polydispersity index of Sg-AgNPs was found to be 0.25 , while that of Sg-AuNPs was 0.10 . The X-ray diffraction pattern of both the silver and gold nanoparticles displayed five diffraction peaks at $2 \theta=38.62^{\circ}, 44.72^{\circ}, 65.02^{\circ}, 77.84^{\circ}$, and $81.90^{\circ}$, which could be attributed to the (111), (200), (220), (311), and (222) planes of face-centered cubic-shaped crystalline silver and gold nanoparticles (Figure 6A and B). Similar results were documented in other studies. ${ }^{7,8}$ In addition, selected area electron diffraction pattern also reconfirmed the crystalline nature (Figure 4). The average crystallite size was determined from X-ray diffraction analysis data using the Scherrer equation. It was found to be $14.63 \mathrm{~nm}$ and $8.01 \mathrm{~nm}$ for $\mathrm{Sg}-\mathrm{AgNPs}$ and $\mathrm{Sg}-\mathrm{AuNPs}$, respectively. The contradiction in the average crystallite diameter obtained from the Scherrer equation and Z-average hydrodynamic diameter from the dynamic light scattering analysis particle size analysis could be attributed to the fact that the hydrodynamic diameter is inclusive of plant biomolecule coatings 


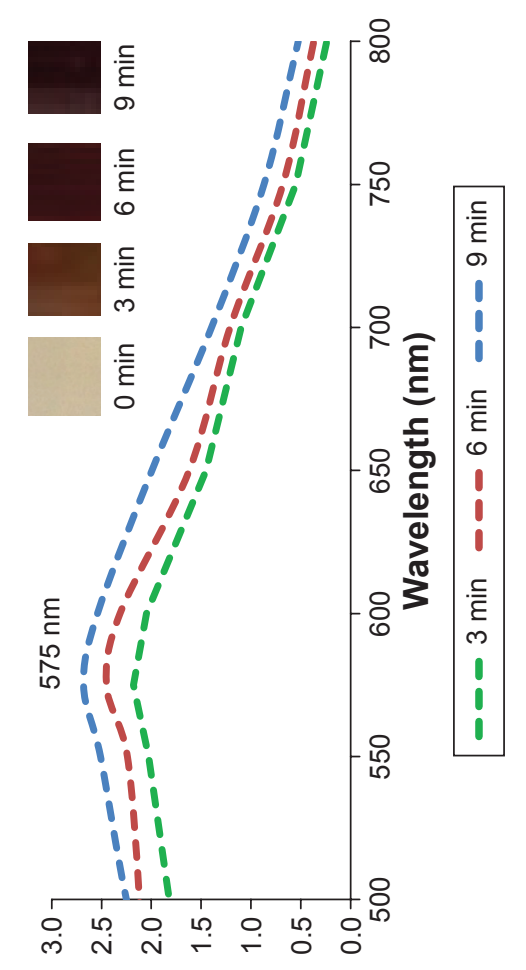

口 (ao) әэuequosq
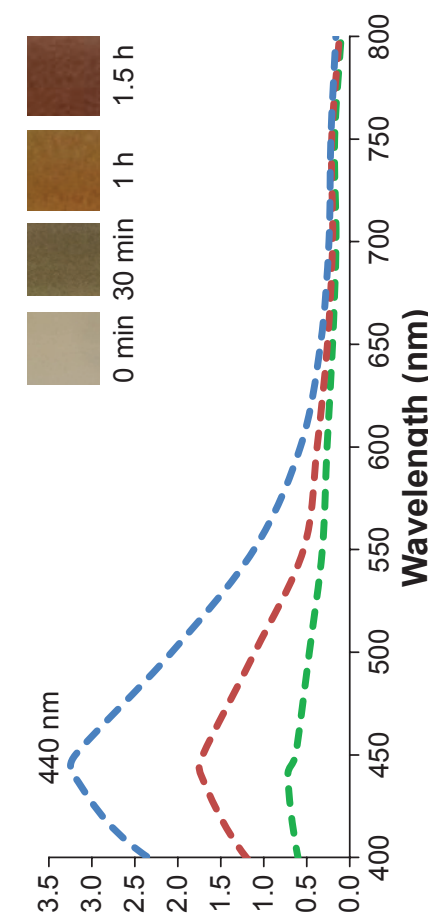

(a०) әэuequosq

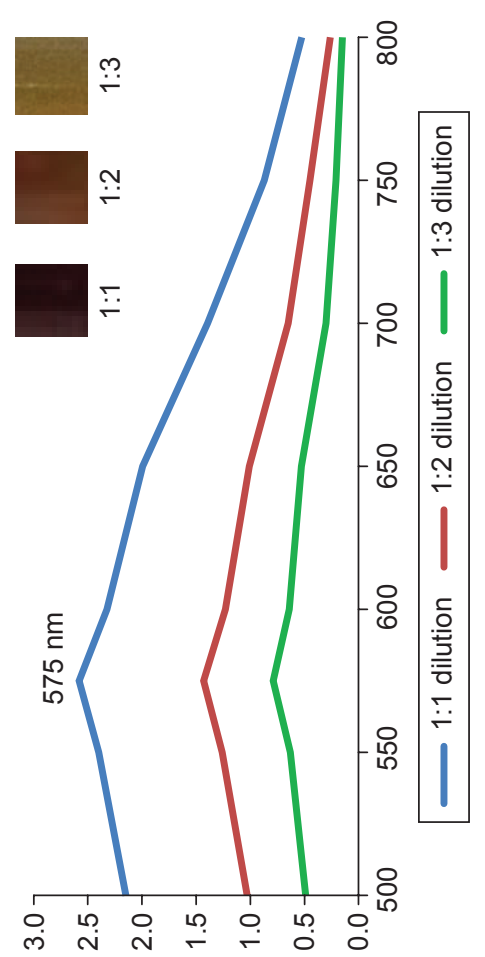

ш (aO) әэuequosq
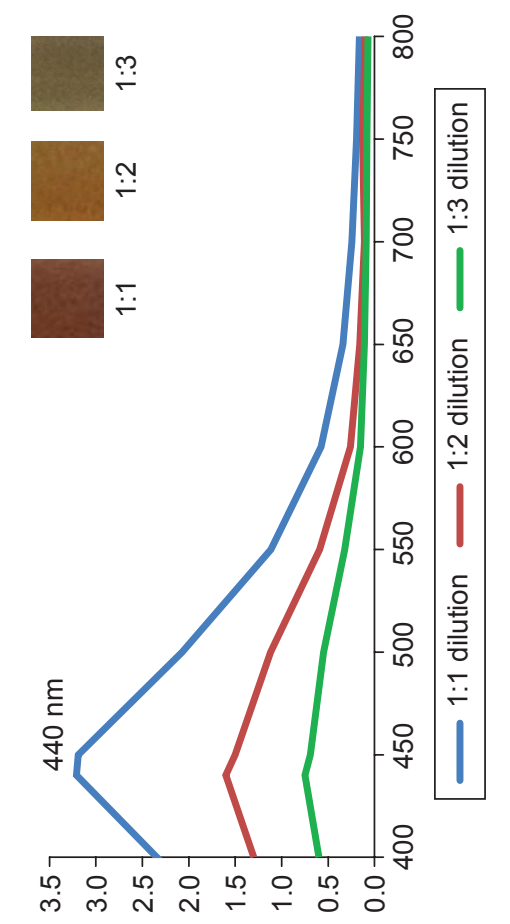

m (a०) әэuequosq $\forall$

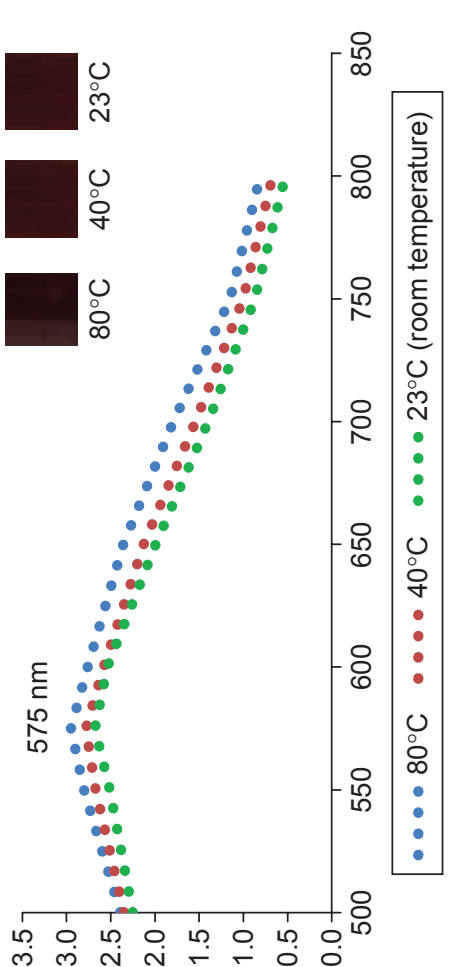

น (aO) әэuequosq
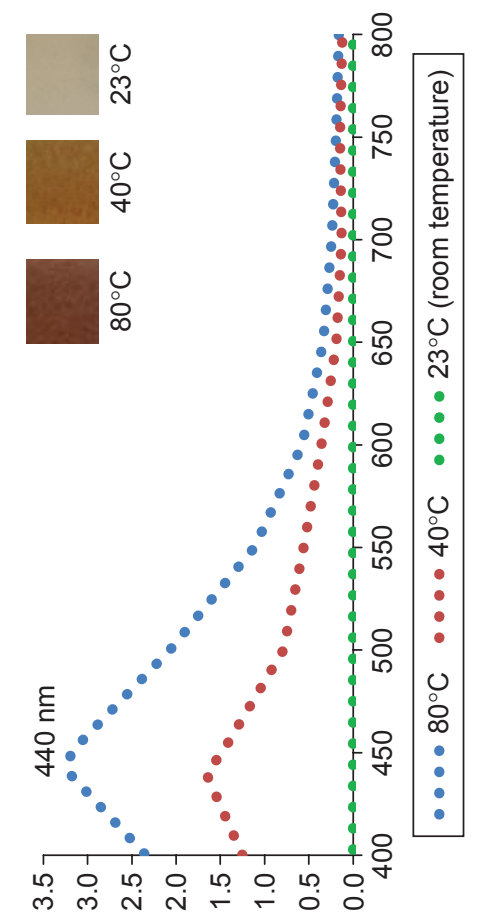

৩ (a०) әэuequosq 

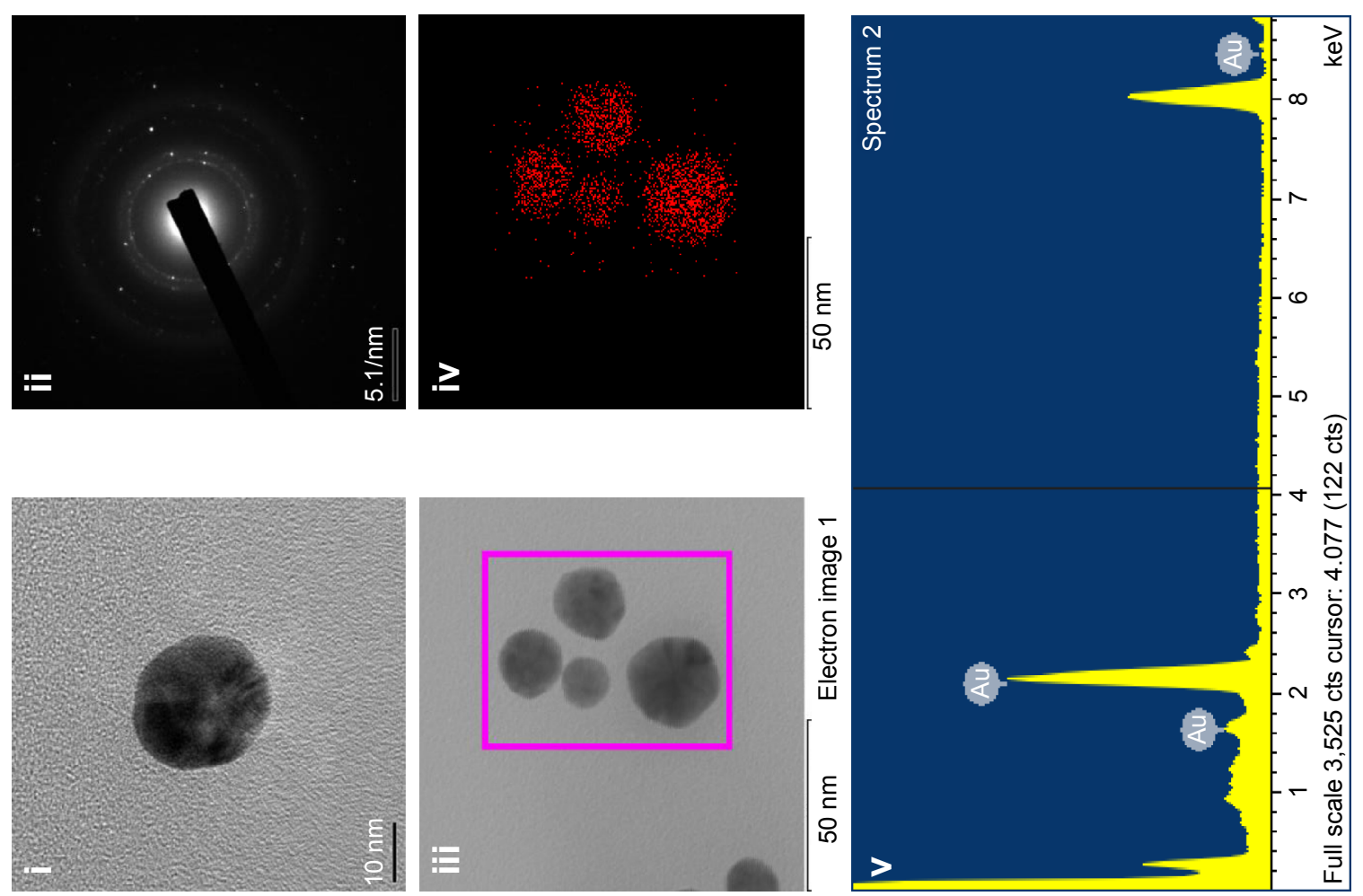

$\mathbf{m}$
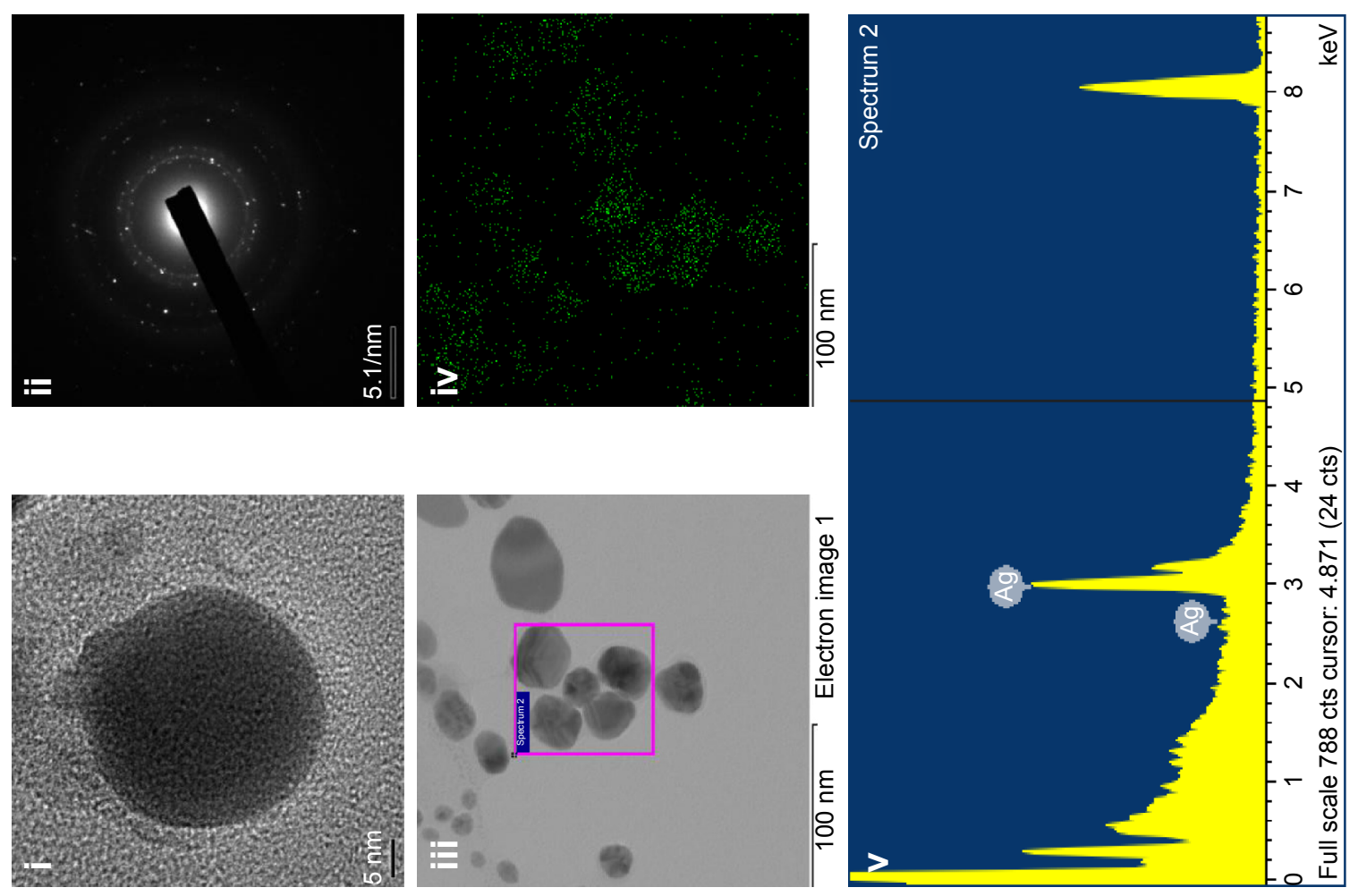

$<$

을.

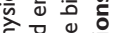

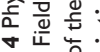

竞苍凯产高 
A

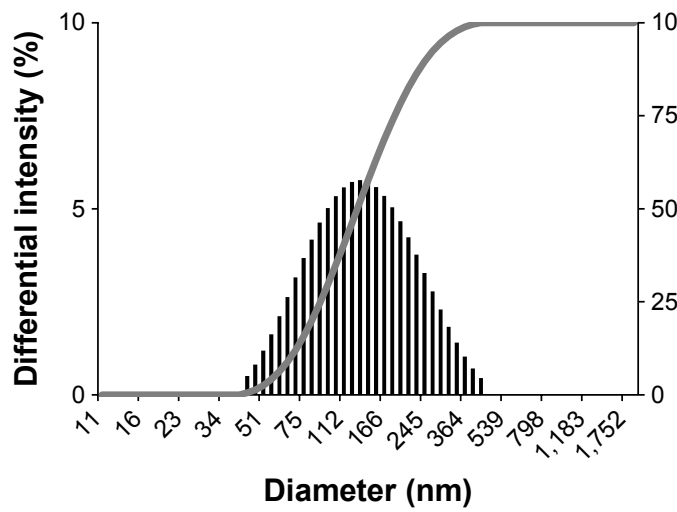

B

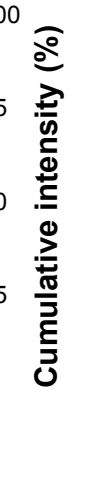

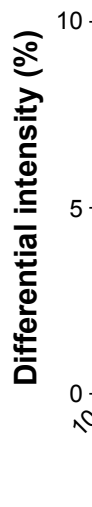

Intensity distribution

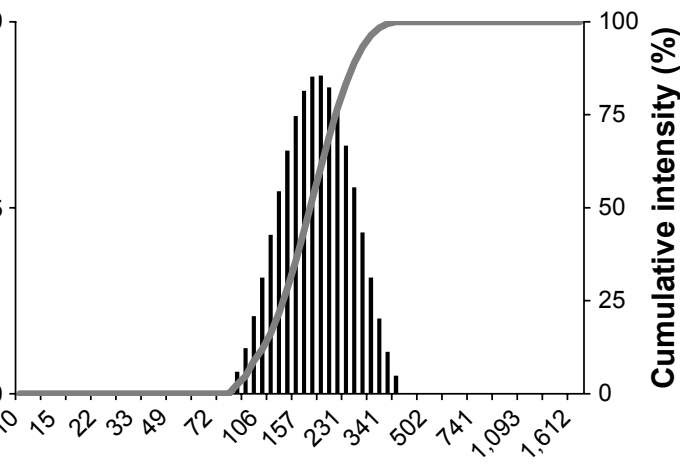

Diameter (nm)

Figure 5 Particle size distribution of Sg-AgNPs (A) and Sg-AuNPs (B) based on intensity as determined by dynamic light scattering analysis.

Note: The Z-average hydrodynamic diameter was 126 and $189 \mathrm{~nm}$ for Sg-AgNPs and Sg-AuNPs, respectively.

Abbreviations: Sg-AgNPs, Siberian ginseng silver nanoparticles; Sg-AuNPs, Siberian ginseng gold nanoparticles.

upon the nanoparticle, whereas the crystallite diameter is solely its core diameter.

FTIR analysis revealed intense bands at 3,420.77, 2,915.90, 2,848.28, 1,627.08, 1,505.59, and 1,017.87 $\mathrm{cm}^{-1}$ for silver nanoparticles, and at $1,644.84,1,324.15$, and $780.38 \mathrm{~cm}^{-1}$ for gold nanoparticles (Figure 6C and D). Bands in the range of 3,500-3,000 $\mathrm{cm}^{-1}$ represent $-\mathrm{N}-\mathrm{H}$ and $\mathrm{OH}-\mathrm{O}$ stretching. The peaks at 2,915.90 and 2,848.16 $\mathrm{cm}^{-1}$ could be attributed to $-\mathrm{CH}_{2}$ asymmetric stretching. The band at $1,633.85 \mathrm{~cm}^{-1}$ could be equated to an amide 1 bond of the polypeptides. ${ }^{25}$ Peaks ranging from 1,650 to $1,450 \mathrm{~cm}^{-1}$ indicate the presence of an aromatic ring and elongation of the aromatic $\mathrm{C}=\mathrm{C}$ bonds. The bands between 1,100 and $1,010 \mathrm{~cm}^{-1}$ in the spectrum were assigned to $\mathrm{C}-\mathrm{O}$ and $\mathrm{C}-\mathrm{H}$ chemical bonds. Peaks ranging from 910-740 $\mathrm{cm}^{-1}$ could be due to the deformation vibration of $\mathrm{C}-\mathrm{H}$ bonds in the phenolic rings. ${ }^{26}$ The deformation vibration of the $\mathrm{C}-\mathrm{C}$ bonds in the phenolic groups creates peaks between 1,500 and $1,400 \mathrm{~cm}^{-1} \cdot{ }^{27}$ In line with this, the peaks
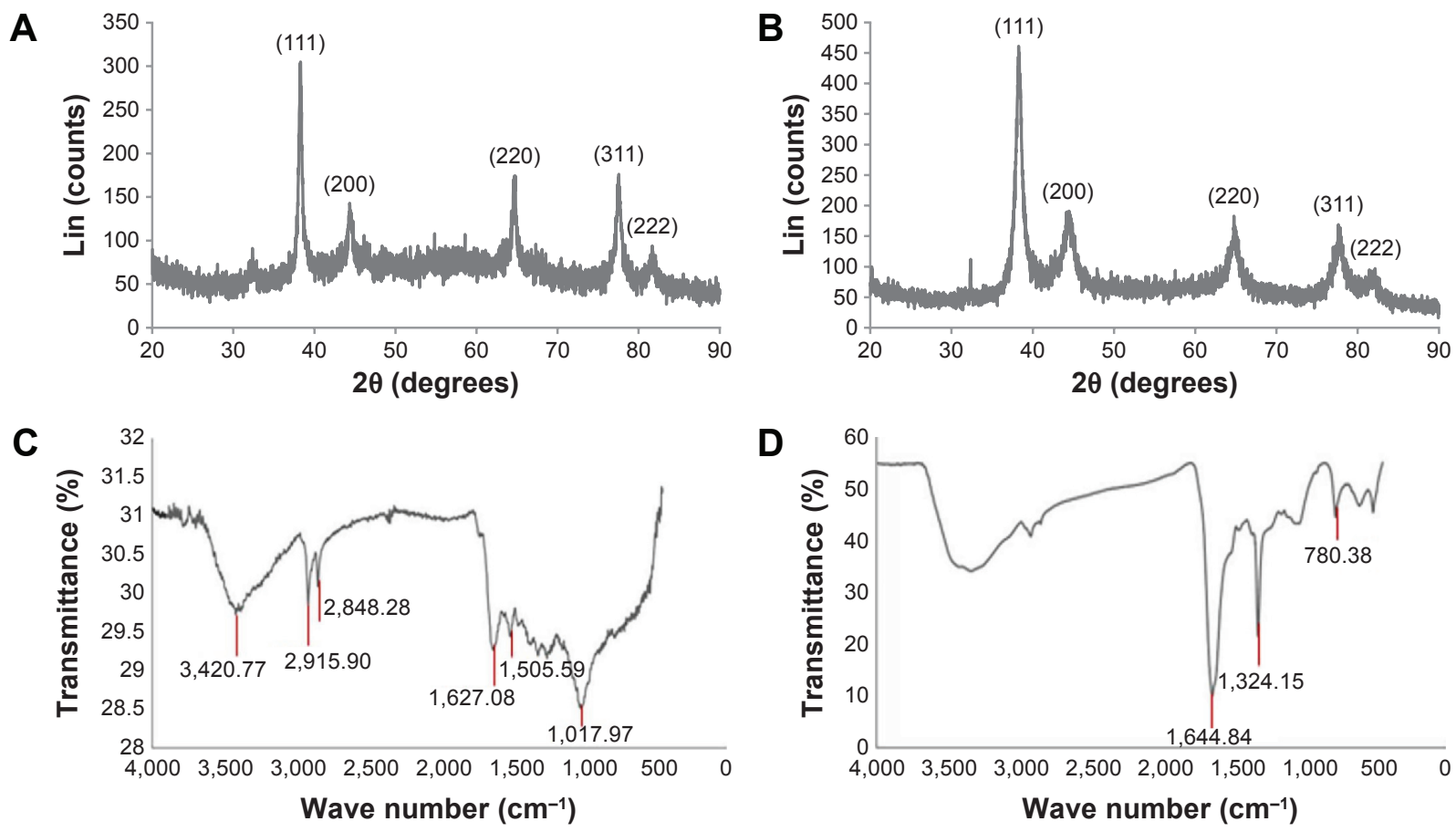

Figure 6 XRD and FTIR analyses of Sg-AgNPs and Sg-AuNPs.

Notes: XRD pattern confirmed the crystalline nature of Sg-AgNPs $(\mathbf{A})$ and Sg-AuNPs $(\mathbf{B})$ and that they are face-centered cubical structures. Scherrer equation indicated that average crystalline diameter was 14.63 and $8.01 \mathrm{~nm}$ for Sg-AgNPs and Sg-AuNPs, respectively. FTIR peaks revealed the nature of the attached biological molecules, which could play a major role in the synthesis and stability of Sg-AgNPs (C) and Sg-AuNPs (D).

Abbreviations: FTIR, Fourier transform infrared analysis; Sg-AgNPs, Siberian ginseng silver nanoparticles; Sg-AuNPs, Siberian ginseng gold nanoparticles; XRD, X-ray diffraction. 
present in the FTIR graph of Sg-AgNPs indicate that proteins and other aromatic organic molecules of E. senticosus could most likely play a key role in the synthesis and stabilization of the silver nanoparticles. In the case of Sg-AuNPs, the obtained data suggest that phenolic compounds of E. senticosus could mainly be responsible for the reduction of $\mathrm{HAuCl}_{4} \cdot 3 \mathrm{H}_{2} \mathrm{O}$ to gold nanoparticles. Moreover, these phenolic compounds are predicted to form a coating around the nanoparticles, thereby contributing to their stability.

The stability of the both Sg-AgNPs and Sg-AuNPs were analyzed by incubating them at room temperature for a period of 1 month. There was no significant deviation in the UV-Vis spectrum in the range of $300-800 \mathrm{~nm}$ after the month-long incubation, confirming the stability of the synthesized nanoparticles.

\section{Effect of the silver and gold nanoparticles on the breast cancer cell line MCF7}

Breast cancer is the most predominant type of cancer in women. In 2015, approximately 231,840 of women in the
US were affected with breast cancer, which accounted for $29 \%$ of the total number of cancer cases in women. ${ }^{28}$ Chemotherapy and radiotherapy are a few of the commonly employed treatments for breast cancer, and unfortunately, these treatments leave serious side effects. ${ }^{29}$ Therefore, studies using nanoparticles in the treatment of cancer have been performed by many research groups to potentially enhance cancer treatment with minimal or no side effects. ${ }^{2}$

In the present study, the synthesized silver and gold nanoparticles were analyzed for cytotoxicity by the MTT assay for 72 hours on HaCaT (normal keratinocyte cell line) and MCF7 (breast cancer cell line). At $10 \mu \mathrm{g} \cdot \mathrm{mL}^{-1}$ concentration, the Sg-AgNPs conferred $40 \%$ cytotoxicity in the MCF7 cell line, whereas there was only $17 \%$ cytotoxicity in the HaCaT cell line (Figure 7A and B). A positive correlation between the dosage of Sg-AgNPs and cytotoxicity rate was documented. Contrastingly, the gold nanoparticles did not exhibit any cytotoxicity in both $\mathrm{HaCaT}$ and MCF7 cell lines (Figure 7C and D). With a concentration as high as $100 \mu \mathrm{g} \cdot \mathrm{mL}^{-1}$ of Sg-AuNPs, viability was $\sim 95 \%$ in both of the cell lines.
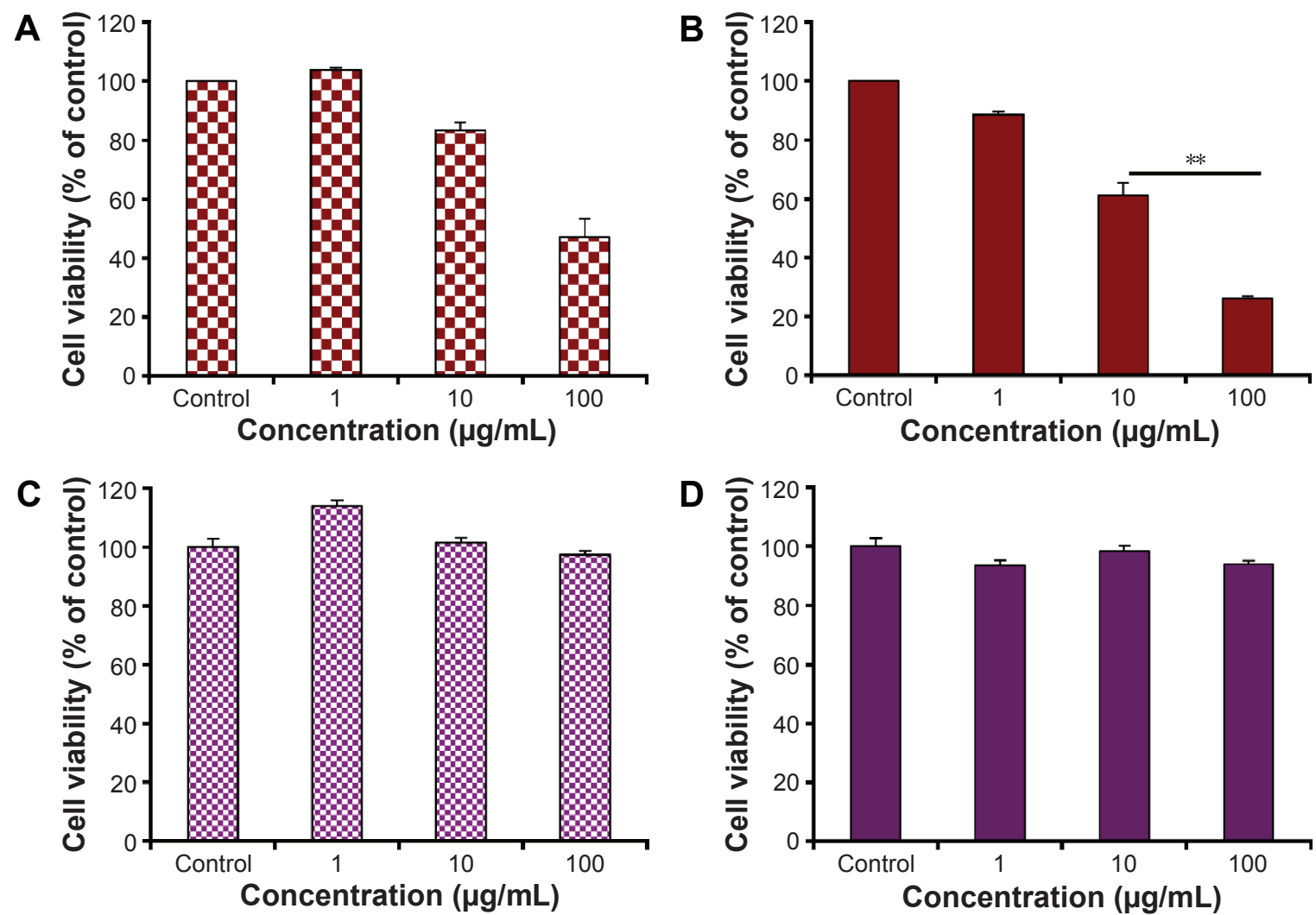

Figure 7 The MTT assay was used to examine the effect of various concentrations of Sg-AgNPs on the viability of the human keratinocyte cell line, HaCaT (A), the breast cancer cell line, MCF7 (B) and the effect of Sg-AuNPs on the viability of the HaCat (C) and MCF7 cell lines (D).

Notes: The cells were incubated with the nanoparticles for 72 hours, and the experiment was repeated three times. Error bars represent the standard deviation ( $\mathrm{n}=3$ ). $* * P<0.00$ I versus control (untreated group). The statistical significance of differences between values was evaluated by one-way ANOVA. At I0 $\mu$ g. $\mathrm{mL}^{-1}$, the Sg-AgNPs led to $40 \%$ cytotoxicity in the MCF7 cell line, but only $17 \%$ cytotoxicity in the HaCat cell line. Sg-AuNPs did not show any cytotoxic effects.

Abbreviations: ANOVA, analysis of variance; MTT, 3-(4,5-dimethyl-2-thiazolyl)-2,5-diphenyl-2H tetrazolium bromide; Sg-AgNPs, Siberian ginseng silver nanoparticles; Sg-AuNPs, Siberian ginseng gold nanoparticles. 
Table I Determination of the antibacterial activity of Sg-AgNPs and Sg-AuNPs by the disc diffusion assay in terms of the zones of inhibition

\begin{tabular}{|c|c|c|c|c|c|c|c|c|}
\hline \multirow[t]{3}{*}{ Microbe } & \multicolumn{8}{|c|}{ Zone of inhibition $(\mathrm{mm})$} \\
\hline & \multicolumn{4}{|l|}{ Sg-AgNPs } & \multicolumn{4}{|l|}{ Sg-AuNPs } \\
\hline & Positive control & $10 \mu \mathrm{g}$ & $20 \mu \mathrm{g}$ & $30 \mu \mathrm{g}$ & Positive control & $10 \mu \mathrm{g}$ & $20 \mu \mathrm{g}$ & $30 \mu \mathrm{g}$ \\
\hline Staphylococcus aureus & $16.5 \pm 0.2$ & $11.0 \pm 0.3$ & $12.3 \pm 0.1$ & $13.8 \pm 0.2$ & $17.9 \pm 0.3$ & 0.0 & 0.0 & 0.0 \\
\hline Bacillus anthracis & $19.0 \pm 0.1$ & $10.7 \pm 0.2$ & $12.0 \pm 0.3$ & $13.2 \pm 0.2$ & $18.0 \pm 0.3$ & 0.0 & 0.0 & 0.0 \\
\hline Vibrio parahaemolyticus & $10.0 \pm 0.4$ & $11.5 \pm 0.3$ & $12.9 \pm 0.2$ & $13.7 \pm 0.1$ & $10.5 \pm 0.2$ & 0.0 & 0.0 & 0.0 \\
\hline Escherichia coli & $18.3 \pm 0.1$ & $12.0 \pm 0.4$ & $12.8 \pm 0.5$ & $13.3 \pm 0.3$ & $17.7 \pm 0.5$ & 0.0 & 0.0 & 0.0 \\
\hline
\end{tabular}

Note: It was interpreted that the Sg-AgNPs were efficient against both gram-positive and gram-negative bacteria.

Abbreviations: Sg-AgNPs, Siberian ginseng silver nanoparticles; Sg-AuNPs, Siberian ginseng gold nanoparticles.

This finding opens up the possibility of using Sg-AuNPs in drug delivery and molecular imaging techniques.

\section{Evaluation of antibacterial activity}

The antibacterial efficacy of the Sg-AgNPs and Sg-AuNPs were evaluated in Luria-Bertani agar against the gram-positive S. aureus (ATCC 6538), B. anthracis (NCTC 10340), and gram-negative V.parahaemolyticus (ATCC 33844), and E. coli (BL21) using the disc diffusion method (Figure S1). Neomycin was used as the positive control for S. aureus and $E$. coli, whereas oleandomycin and vancomycin were employed as positive controls for B. anthracis and V.parahaemolyticus, respectively. In the case of $\mathrm{Sg}-\mathrm{AgNPs}$, the minimum inhibitory concentration (MIC) was $9 \mu \mathrm{g} \cdot \mathrm{mL}^{-1}$ against all of the bacteria. The zone of inhibition increased with an increase in concentration. On the other hand, Sg-AuNPs did not show any zone of inhibition irrespective of the concentration used. These results are tabulated in Table 1. This clearly indicates that the silver nanoparticles confer toxicity against both gram-positive and gram-negative bacteria, as reported in the past. ${ }^{8,30}$ The mechanism related to the antibacterial activity of Sg-AgNPs remains to be elucidated. Silver nanoparticles have the capacity to damage the cell wall of both grampositive and gram-negative bacteria, thereby killing them. ${ }^{31}$ In line with this, Sg-AgNPs might have degraded the cell wall, leading to the death of the bacteria. However, further studies are required to confirm this assumption. Sg-AgNPs have the potential to be utilized in the disinfection of surgical instruments, thereby preventing cross-contamination and enhancing safety levels in hospitals.

\section{Assessment of antioxidant activity}

The free radical scavenging efficacy of $\mathrm{Sg}$-AgNPs and Sg-AuNPs was determined through the DPPH assay. Upon accepting hydrogen $(\mathrm{H})$ from the antioxidant, DPPH reduces to $\mathrm{DPPH}_{2}$, thus resulting in the change of color from purple to yellow which is associated with a characteristic decrease in absorbance at $515 \mathrm{~nm} .{ }^{32,33}$ Approximately 50\% DPPH inhibition was recorded at 100 and $250 \mu \mathrm{g} \cdot \mathrm{mL}^{-1}$ concentrations of Sg-AgNPs and Sg-AuNPs, respectively. In addition, Sg-AgNPs and Sg-AuNPs demonstrated significantly higher antioxidant activity than their corresponding salts (Figure 8).

During unfavorable conditions, reactive oxygen species levels are elevated in human cells, which lead to cancer, accelerated aging, and other major disorders. ${ }^{34,35}$ In the present study, MTT results indicated that Sg-AuNPs did not display any cytotoxicity to both the $\mathrm{HaCaT}$ and MCF7 cell lines. Therefore, Sg-AuNPs could be effectively employed to scavenge free radicals synthesized in the cell in response to multiple stresses. The antioxidant potential of gold nanoparticles has been reported earlier. ${ }^{36}$ Moreover, Sg-AuNPs could also be combined with cosmetics to enhance skin texture and prevent aging symptoms.

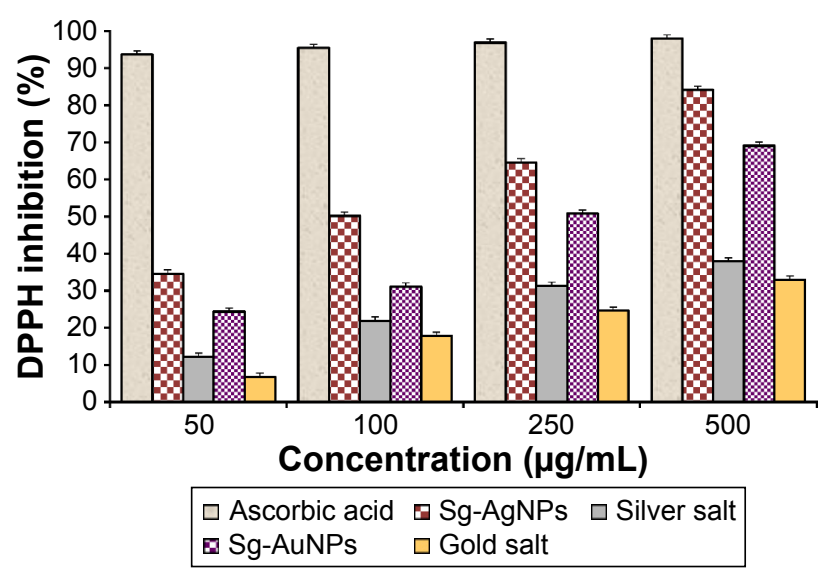

Figure 8 The DPPH inhibition assay elucidates the antioxidant potential of the biosynthesized Sg-AgNPs and Sg-AuNPs.

Notes: Approximately $50 \%$ of DPPH inhibition was recorded at the 100 and $250 \mu \mathrm{g} \cdot \mathrm{mL}^{-1}$ concentration of the Sg-AgNPs and Sg-AuNPs, respectively. It can be inferred that the antioxidant efficiency of the nanoparticles is significantly higher than their corresponding salts.

Abbreviations: DPPH, 2,2-diphenyl-I-picrylhydrazyl; Sg-AgNPs, Siberian ginseng silver nanoparticles; Sg-AuNPs, Siberian ginseng gold nanoparticles. 


\section{Conclusion}

This report describes a method for the biological synthesis of silver and gold nanoparticles from the herbal adaptogen E. senticosus, which is simple, efficient, and ecofriendly. Physicochemical characterization revealed the structural and chemical properties of the nanoparticles. MTT analysis indicated that at $10 \mu \mathrm{g} \cdot \mathrm{mL}^{-1}, \mathrm{Sg}-\mathrm{AgNPs}$ could be effectively employed in breast cancer treatments. As Sg-AuNPs did not possess cytotoxicity across the selected concentration range, they could potentially be used as carriers in drug delivery as well as in molecular imaging techniques. Sg-AgNPs exhibited inhibitory effects against S. aureus (ATCC 6538), B. anthracis (NCTC 10340), V. parahaemolyticus (ATCC 33844), and E. coli (BL21), which sheds light on their application as a sterilizing agent for surgical instruments. In addition, both silver and gold nanoparticles were found to be efficient antioxidants. As the MTT analysis indicated that Sg-AuNPs were not cytotoxic, they can be effectively used in combination with cosmetics to prevent the symptoms of aging. We strongly believe that this study would open up doors for large-scale utilization of the multifunctional $\mathrm{Sg}-\mathrm{AgNPs}$ and $\mathrm{Sg}$-AuNPs, which would indirectly aid in reaping the benefits of endemic E. senticosus.

\section{Acknowledgments}

This research was supported by the Korea Institute of Planning \& Evaluation for Technology in Food, Agriculture, Forestry \& Fisheries (KIPET number: 313038-03-2-SB010), Republic of Korea, and also supported from a grant from the Next-Generation BioGreen 21 Program (SSAC, grant number: PJ0120342016), Rural Development Administration, Republic of Korea.

\section{Disclosure}

The authors report no conflicts of interest in this work.

\section{References}

1. Fakruddin M, Hossain Z, Afroz H. Prospects and applications of nanobiotechnology: a medical perspective. J Nanobiotechnol. 2012;10(1):31.

2. Singh P, Kim YJ, Zhang D, Yang DC. Biological synthesis of nanoparticles from plants and microorganisms. Trends Biotechnol. Epub 2016 Mar 1.

3. Mathiyalagan R, Subramaniyam S, Kim YJ, Kim YC, Yang DC. Ginsenoside compound K-bearing glycol chitosan conjugates: synthesis, physicochemical characterization, and in vitro biological studies. Carbohydr Polym. 2014;112:359-366.

4. Mathiyalagan R, Subramaniyam S, Kim YJ, et al. Synthesis and pharmacokinetic characterization of a $\mathrm{pH}$-sensitive polyethylene glycol ginsenoside CK (PEG-CK) conjugate. Biosci Biotechnol Biochem. 2014; 78(3):466-468
5. Wong KKY, Liu X. Silver nanoparticles - the real "silver bullet" in clinical medicine? Med Chem Comm. 2010;1(2):125-131.

6. Ghosh P, Han G, De M, Kim CK, Rotello VM. Gold nanoparticles in delivery applications. Adv Drug Deliv Rev. 2008;60(11):1307-1315.

7. Sharma B, Purkayastha DD, Hazra S, et al. Biosynthesis of gold nanoparticles using a freshwater green alga, Prasiola crispa. Mater Lett. 2014; 116:94-97.

8. Wang C, Mathiyalagan R, Kim YJ, et al. Rapid green synthesis of silver and gold nanoparticles using Dendropanax morbifera leaf extract and its anticancer activity. Int J Nanomedicine. In press 2016.

9. Wang C, Singh P, Kim YJ, et al. Characterization and antimicrobial application of biosynthesized gold and silver nanoparticles by using Microbacterium resistens. Artif Cells Nanomed Biotechnol. Epub 2015 Nov 23.

10. Huang L, Zhao H, Huang B, Zheng C, Peng W, Qin L. Acanthopanax senticosus: review of botany, chemistry and pharmacology. Die Pharmazie. 2011;66(2):83-97.

11. Sun YL, Liu LD, Lin DL, Hong SK. Eleutherococcus senticosus as a crude medicine: review of biological and pharmacological effects. J Medl Plants Res. 2011;5(25):5946-5952.

12. Murthy HN, Kim YS, Georgiev MI, Paek KY. Biotechnological production of eleutherosides: current state and perspectives. Appl Microbiol Biotechnol. 2014;98(17):7319-7329.

13. Yoon TJ, Yoo YC, Lee SW, et al. Anti-metastatic activity of Acanthopanax senticosus extract and its possible immunological mechanism of action. J Ethnopharmacol. 2004;93(2):247-253.

14. Wang X, Hai C, Liang X, Yu S, Zhang W, Li Y. The protective effects of Acanthopanax senticosus Harms aqueous extracts against oxidative stress: role of Nrf2 and antioxidant enzymes. JEthnopharmacol. 2010;127(2):424-432.

15. Lee S, Shin D-S, Oh K-B, Shin KH. Antibacterial compounds from the leaves of Acanthopanax senticosus. Arch Pharm Res. 2003; 26(1):40-42.

16. Kang JS, Linh PT, Cai XF, Kim HS, Lee JJ, Kim YH. Quantitative determination of eleutheroside B and E from Acanthopanax species by high performance liquid chromatography. Arch Pharm Res. 2001;24(5): $407-411$.

17. Jin Y, Kim YJ, Jeon JN, et al. Effect of white, red and black ginseng on physicochemical properties and ginsenosides. Plant Foods Hum Nutr. 2015;70(2):141-145.

18. Mubarak NM, Wong JR, Tan KW, et al. Immobilization of cellulase enzyme on functionalized multiwall carbon nanotubes. J Mol Catal B Enzym. 2014;107:124-131.

19. Ramya S, Shanmugasundaram T, Balagurunathan R. Biomedical potential of actinobacterially synthesized selenium nanoparticles with special reference to anti-biofilm, anti-oxidant, wound healing, cytotoxic and anti-viral activities. J Trace Elem Med Biol. 2015; 32:30-39.

20. Ainsworth EA, Gillespie KM. Estimation of total phenolic content and other oxidation substrates in plant tissues using Folin-Ciocalteu reagent. Nat Protoc. 2007;2(4):875-877.

21. Wood IP, Elliston A, Ryden P, Bancroft I, Roberts IN, Waldron KW Rapid quantification of reducing sugars in biomass hydrolysates: improving the speed and precision of the dinitrosalicylic acid assay. Biomass Bioenergy. 2012;44:117-121.

22. Miller GL. Use of dinitrosalicylic acid reagent for determination of reducing sugar. Anal Chem. 1959;31(3):426-428.

23. Mittal AK, Chisti Y, Banerjee UC. Synthesis of metallic nanoparticles using plant extracts. Biotechnol Adv. 2013;31(2):346-356.

24. Singh P, Kim YJ, Wang C, Mathiyalagan R, Yang DC. The development of a green approach for the biosynthesis of silver and gold nanoparticles by using Panax ginseng root extract, and their biological applications. Artif Cells Nanomed Biotechnol. 2016;44(4):1150-1157.

25. Hromiš NM, Lazić VL, Markov SL, et al. Optimization of chitosan biofilm properties by addition of caraway essential oil and beeswax J Food Eng. 2015;158:86-93. 
26. Oladoja NA, Alliu YB, Ofomaja AE, Unuabonah IE. Synchronous attenuation of metal ions and colour in aqua stream using tannin-alum synergy. Desalination. 2011;271(1-3):34-40.

27. Özacar M, Soykan C, Şengil İA. Studies on synthesis, characterization, and metal adsorption of mimosa and valonia tannin resins. J Appl Polym Sci. 2006;102(1):786-797.

28. Siegel RL, Miller KD, Jemal A. Cancer statistics, 2015. CA Cancer J Clin. 2015;65(1):5-29.

29. DeSantis CE, Lin CC, Mariotto AB, et al. Cancer treatment and survivorship statistics, 2014. CA Cancer J Clin. 2014;64(4):252-271.

30. Singh P, Kim YJ, Singh H, et al. Biosynthesis, characterization, and antimicrobial applications of silver nanoparticles. Int J Nanomedicine. 2015;10:2567-2577.

31. Khatoon N, Ahmad R, Sardar M. Robust and fluorescent silver nanoparticles using Artemisia annua: biosynthesis, characterization and antibacterial activity. Biochem Eng J. 2015;102:91-97.
32. Mishra K, Ojha H, Chaudhury NK. Estimation of antiradical properties of antioxidants using DPPH assay: a critical review and results. Food Chemistry. 2012;130(4):1036-1043.

33. Blois MS. Antioxidant determinations by the use of a stable free radical. Nature. 1958;181(4617):1199-1200.

34. Ziech D, Anestopoulos I, Hanafi R, et al. Pleiotrophic effects of natural products in ROS-induced carcinogenesis: the role of plant-derived natural products in oral cancer chemoprevention. Cancer Lett. 2012;327(1): 16-25.

35. Valko M, Leibfritz D, Moncol J, Cronin MT, Mazur M, Telser J. Free radicals and antioxidants in normal physiological functions and human disease. Int J Biochem Cell Biol. 2007;39(1):44-84.

36. Nie Z, Liu KJ, Zhong C-J, et al. Enhanced radical scavenging activity by antioxidant-functionalized gold nanoparticles: a novel inspiration for development of new artificial antioxidants. Free Radic Biol Med. 2007; 43(9):1243-1254. 


\section{Supplementary material}
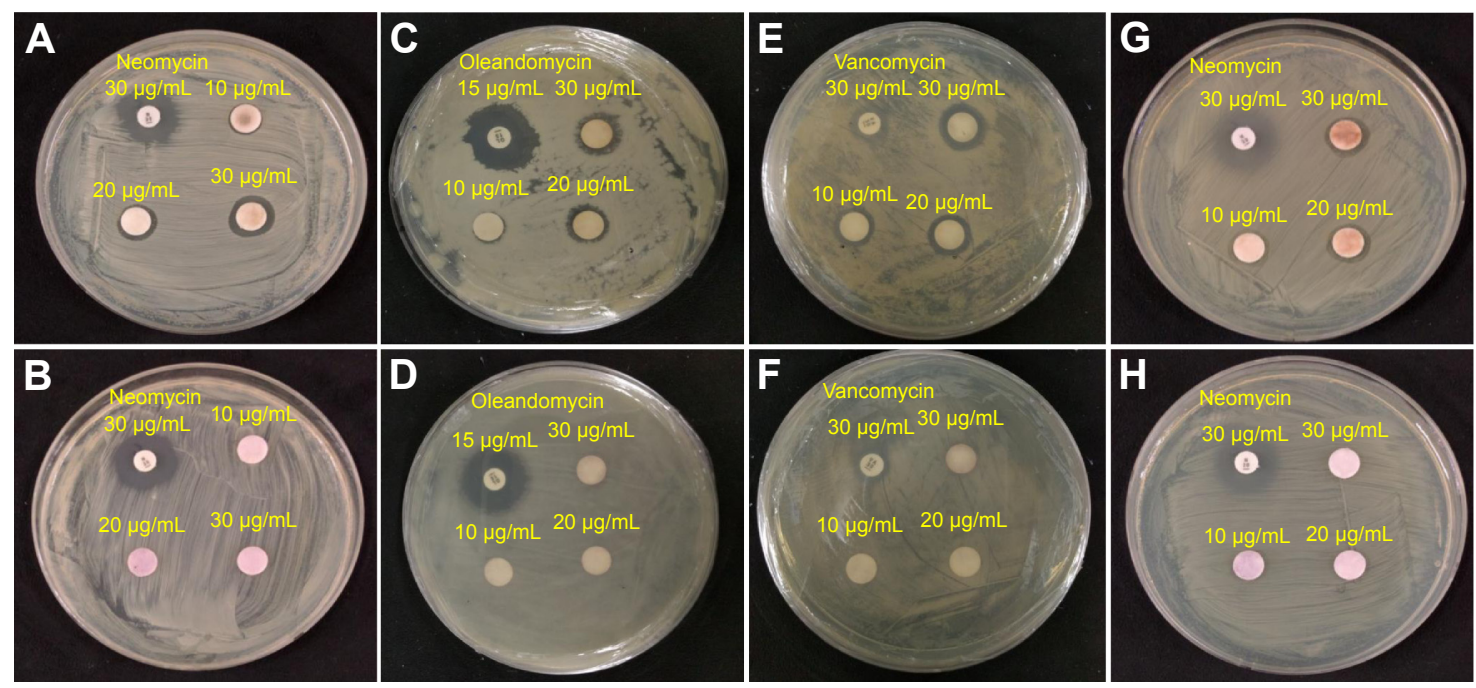

Figure SI The disc diffusion method demonstrates the effects of various concentrations of biosynthesized nanoparticles.

Notes: The effects of various concentrations $\left(10,20\right.$, and $\left.30 \mu \mathrm{g} \cdot \mathrm{mL}^{-1}\right)$ of biosynthesized nanoparticles on the gram-positive Staphylococcus aureus (Sg-AgNPs [A] and Sg-AuNPs [B]) and Bacillus anthracis (Sg-AgNPs [C] and Sg-AuNPs [D]). Similarly, their antibacterial effect was tested on gram-negative Vibrio parahaemolyticus (Sg-AgNPs [E] and Sg-AuNPs $[\mathbf{F}]$ ) and Escherichia coli (Sg-AgNPs [G] and Sg-AuNPs $[\mathbf{H}])$. In the case of Sg-AgNPs, the zone of inhibition increased with an increase in the concentration of nanoparticles, whereas Sg-AuNPs did not show any antibacterial activity in the selected concentration range.

Abbreviations: Sg-AgNPs, Siberian ginseng silver nanoparticles; Sg-AuNPs, Siberian ginseng gold nanoparticles.

International Journal of Nanomedicine

\section{Publish your work in this journal}

The International Journal of Nanomedicine is an international, peerreviewed journal focusing on the application of nanotechnology in diagnostics, therapeutics, and drug delivery systems throughout the biomedical field. This journal is indexed on PubMed Central, MedLine, CAS, SciSearch ${ }^{\circledR}$, Current Contents ${ }^{\circledR} /$ Clinical Medicine,

\section{Dovepress}

Journal Citation Reports/Science Edition, EMBase, Scopus and the Elsevier Bibliographic databases. The manuscript management system is completely online and includes a very quick and fair peer-review system, which is all easy to use. Visit http://www.dovepress.com/ testimonials.php to read real quotes from published authors.

\footnotetext{
Submit your manuscript here: http://www.dovepress.com/international-journal-of-nanomedicine-journal
} 